\title{
Heart rate variability in left ventricular hypertrophy
}

Mahendra K Mandawat, David R Wallbridge, Stuart D Pringle, Abdulla A S Riyami, Shahid Latif, Peter W Macfarlane, A Ross Lorimer, Stuart M Cobbe

\begin{abstract}
Background-Electrocardiographic left ventricular hypertrophy and strain are associated with increased cardiac morbidity and mortality. Impaired cardiac autonomic function, assessed noninvasively by spontaneous heart rate variability on Holter monitoring, is associated with an increased risk of sudden death after myocardial infarction.
\end{abstract}

Aim-To study the effect of left ventricular hypertrophy on heart rate variability. Patients-36 controls and 154 patients with left ventricular hypertrophy (94 with hypertension and 60 with aortic valve disease).

Setting-Tertiary referral centre.

Methods-Heart rate variability was measured on $24 \mathrm{~h}$ Holter recordings by non-spectral methods. Left ventricular mass index and fractional shortening were measured by echocardiography.

Results-Patients with left ventricular hypertrophy had a higher left ventricular mass index $(P<0.001)$ and reduced heart rate variability $(P<0.001)$ compared with those of the controls. A continuous inverse relation was apparent between heart rate variability and left ventricular mass index $(r=-0.478, P<0.001)$. Heart rate variability was not affected by age, the presence of coronary artery disease in patients with left ventricular hypertrophy, or $\beta$ blocker treatment for hypertension. Multivariate analysis showed that left ventricular mass index is the most important determinant of heart rate variability.

Conclusion-Heart rate variability is significantly reduced in patients with left ventricular hypertrophy secondary to hypertension or aortic valve disease. A continuous inverse relation exists between heart rate variability and left ventricular mass index. Impaired cardiac autonomic function in left ventricular hypertrophy may contribute to the mechanism of sudden death.

(Br Heart $\mathcal{F} 1995 ; 73: 139-144)$

Keywords: left ventricular hypertrophy, heart rate variability.

Electrocardiographic left ventricular hypertrophy and strain are associated with increased cardiovascular mortality and sudden death.
This risk is independent of the level of blood pressure and other cardiovascular risk factors, ${ }^{12}$ but an increased incidence of ventricular arrhythmia has been reported. ${ }^{34}$ Experimental and clinical evidence each suggests that impaired cardiac autonomic control may be a risk factor for sudden cardiac death. Increased sympathetic activity is associated with a reduced threshold for ventricular fibrillation, and thereby potentially increases mortality, whilst increased parasympathetic activity has the opposite effect, increasing the threshold for ventricular fibrillation. ${ }^{56}$ Recently, attention has focused on spontaneous heart rate variability on Holter monitoring as a non-invasive measure of cardiac autonomic function. ${ }^{78}$ Decreased heart rate variability, indicating either increased sympathetic activity or reduced vagal activity, is associated with increased risk of sudden death in coronary artery disease. ${ }^{9} \mathrm{~A}$ reduction in heart rate variability has been reported in patients with diabetes mellitus, ${ }^{10}$ heart failure, ${ }^{11}$ and after myocardial infarction, ${ }^{12}{ }^{13}$ but there is little experience in patients with left ventricular hypertrophy. ${ }^{14} 15$

The present study was undertaken to compare heart rate variability in a control population with that in patients having electrocardiographic left ventricular hypertrophy and strain secondary to either hypertension or aortic valve disease. Possible reasons for any difference, including left ventricular mass, coronary artery disease and ventricular function are explored as are the possible consequences on ventricular arrhythmia.

\section{Patients and methods}

There were three study groups: controls, patients with hypertension, and those with aortic valve disease.

Thirty six asymptomatic volunteers were recruited on the basis of age from a larger cohort of local government employees undergoing non-invasive cardiac assessment. The age range of these volunteers was chosen so that the mean age would match that of the patients. By definition, there was no history of diabetes or hypertension, and no routine medication. Physical examination and resting electrocardiogram (ECG) were normal.

Ninety four patients were selected from an ongoing study investigating the mechanisms of sudden cardiac death in 102 subjects with electrocardiographic left ventricular hypertrophy and strain presenting consecutively to 
the hypertension clinic. ${ }^{16}$ All patients had essential hypertension and inclusion in the present study was determined by the availability of a suitable $24 \mathrm{~h}$ ambulatory ECG (of adequate quality; no atrial fibrillation, atrioventricular block, or sick sinus syndrome; and no permanent pacemaker). Five patients had suffered a previous myocardial infarction more than 1 year before the study and all but eight continued their usual medication, including $\beta$ blockers, during the investigation.

Sixty patients (32 aortic stenosis, 10 aortic incompetence, and 18 mixed aortic valve disease) were selected from a separate ongoing study of 90 consecutive patients requiring invasive assessment for significant aortic valve disease. ${ }^{17}$ Inclusion was determined by the availability of a suitable $24 \mathrm{~h}$ ambulatory ECG (as described earlier). Regular medication was continued, but no patient was receiving $\beta$ blocker or antiarrhythmic treatment.

All patients underwent $24 \mathrm{~h}$ ambulatory ECG monitoring. Echocardiography was performed to assess left ventricular mass ${ }^{18}$ and fractional shortening. Coronary angiography was undertaken in all patients with aortic valve disease. This technique was considered in all patients with hypertension, except those who were thought to be too old or frail, and performed in 47 .

The study was approved by the Ethical Committee of Glasgow Royal Infirmary. Written informed consent was obtained for invasive procedures and verbal consent for other investigations.

\section{ELECTROCARDIOGRAPHY}

A 12 lead ECG was recorded and measured using the Glasgow CARE (computer assisted reporting of electrocardiogram) system. ${ }^{19} \mathrm{Left}$ ventricular hypertrophy and strain was defined as ST segment depression $\geqslant 0.02 \mathrm{mV}$ and $\mathrm{T}$ wave inversion of $0.1 \mathrm{mV}$ or more in one of leads $\mathrm{I}, \mathrm{aVL}, \mathrm{V} 5$ or V6 in the presence of voltage criteria (SV1 + RV5 > 3.5 mV) for left ventricular hypertrophy.

\section{ECHOCARDIOGRAPHY}

The echocardiograms were obtained with an Ultramark 8 machine (Advanced Technology Laboratories, Bathell, USA) with a $3 \mathrm{MHz}$ transducer. Patients were positioned in the $45^{\circ}$ left lateral position and views giving best delineation of the interventricular septum and left ventricular posterior wall were chosen in the parasternal long axis view. Measurements were made according to the recommendations of the Penn convention. ${ }^{20}$ The left ventricular mass was calculated by the anatomically validated formula of Devereux and Reicheck ${ }^{18}$ :

LVM $=1.04\left[(\text { IVS + PWLV + LVIDD })^{3}-(\text { LVIDD })^{3}\right]-13.6 \mathrm{~g}$ where LVM is the left ventricular mass $(\mathrm{g})$, IVS is the interventricular septal thickness (cm), PWLV is the thickness of the posterior wall of left ventricle $(\mathrm{cm})$, and LVIDD is the left ventricular internal dimension at the end of diastole $(\mathrm{cm})$.

The ventricular mass was divided by body surface area to obtain the left ventricular mass index (LVMI). The body surface area was obtained from the equation ${ }^{21}$ :

$\mathrm{BSA}=0.0001 \times 71.84 \times \mathrm{Wt}^{0.425} \times \mathrm{Ht}^{0.725}$

where BSA is body surface area $\left(\mathrm{m}^{2}\right), \mathrm{Wt}$ is weight $(\mathrm{kg})$, and $\mathrm{Ht}$ is height $(\mathrm{cm})$.

Echocardiographic left ventricular hypertrophy was diagnosed when left ventricular mass index exceeded $131 \mathrm{~g} / \mathrm{m}^{2}$ in men and $108 \mathrm{~g} / \mathrm{m}^{2}$ in women. ${ }^{18}$ Fractional shortening was taken as a measure of left ventricular function and was obtained as follows ${ }^{22}$ :

Fractional shortening $(\%)=($ LVIDd - LVIDs $) / L V I D d$

where LVIDd and LVIDs are the left ventricular internal diameters at end diastole and end systole, respectively.

\section{AMBULATORY ELECTROCARDIOGRAPHY}

Twenty four $h$ ambulatory ECGs were recorded using bipolar leads CM5 and a modified V2 on a Medilog II FM device (Oxford Instruments, Oxford, UK). Tapes were analysed by a single experienced technician using a computer assisted technique. ${ }^{23}$ Significant ventricular arrhythmia was defined as the presence of $>30$ ventricular extrasystoles per $h$, complicated ventricular extrasystole (couplets, triplets, or R-on-T), or ventricular tachycardia. ${ }^{24}$

\section{HEART RATE VARIABILITY}

Ambulatory ECG tapes were replayed using a Pathfinder II (Reynolds Medical, Hertford, UK) high speed analyser at 60 times the original speed. The analysis system, initially trained by an operator, differentiated between normal and abnormal QRS complexes. The triggering level for abnormal QRS complexes was adjusted by the same operator throughout the study in an identical manner to minimise the differences between successive analyses. All abnormal QRS complexes and their adjacent intervals were excluded from the calculation of heart rate variability. The signals on the oscilloscope were closely monitored throughout by the operator to exclude tapes with intermittent atrial fibrillation and other non-sinus rhythms. The Pathfinder generated an external impulse synchronous with each QRS complex identified and another if the QRS complex was normal in configuration. This digitised information was passed to an ECG analyser interface unit. This prolonged the duration of the external impulses which were transferred via a parallel link to an IBM compatible personal computer that effectively stored each RR interval. Cycle lengths differing by less than $20 \%$ from the preceding sinus cycle length $(\mathrm{NN})$ were stored for further analysis.

Heart rate variability was calculated as:

1. SDNN, which is the standard deviation of all NN intervals over $24 \mathrm{~h}^{25}$

2. Triangular index, which was calculated by dividing the total number of $\mathrm{NN}$ intervals by the modal NN interval frequency. ${ }^{26}$

3. SDANN, which is the standard deviation of the mean $\mathrm{NN}$ interval for all $5 \mathrm{~min}$ segments of a $24 \mathrm{~h}$ recording. 


\begin{tabular}{|c|c|c|c|}
\hline & $\begin{array}{l}\text { Normal } \\
\text { controls }\end{array}$ & $\begin{array}{l}\text { Patients with left ventricular } \\
\text { hypertrophy secondary to hypertension }\end{array}$ & $\begin{array}{l}\text { Patients with left ventricular } \\
\text { hypertrophy secondary to aortic valve } \\
\text { disease }\end{array}$ \\
\hline $\begin{array}{l}\text { n } \\
\text { Male/Female } \\
\text { Mean (SD) age (years) } \\
\text { Mean (SD) left ventricular mass index }\left(\mathrm{g} / \mathrm{m}^{2}\right) \\
\text { Mean (SD) fractional shortening (\%) } \\
\text { Mean (SD) NN interval (ms) } \\
\text { Mean (SD) SDNN (ms) } \\
\text { Mean (SD) triangular index (ms) } \\
\text { Mean (SD) SDANN (ms) }\end{array}$ & $\begin{array}{l}36 \\
30 / 6 \\
58 \cdot 7(4 \cdot 8) \\
110 \cdot 0(32 \cdot 5) \\
35 \cdot 3(7 \cdot 5) \\
820 \cdot 6(104 \cdot 0) \\
138 \cdot 6(27 \cdot 0) \\
35 \cdot 2(8 \cdot 6) \\
136 \cdot 6(40 \cdot 6)\end{array}$ & $\begin{array}{l}94 \\
74 / 20 \\
56 \cdot 5(10 \cdot 2) \\
203 \cdot 7(50 \cdot 8)^{\star \star} \\
38 \cdot 4(13 \cdot 6) \\
839 \cdot 9(155 \cdot 9) \\
104 \cdot 5(34 \cdot 7)^{\star \star} \\
28 \cdot 1(8 \cdot 7)^{\star \star} \\
96 \cdot 1(37 \cdot 1)^{\star \star}\end{array}$ & $\begin{array}{l}60 \\
36 / 24 \\
58 \cdot 8(11 \cdot 5) \\
219 \cdot 5(70 \cdot 3)^{\star \star} \\
33 \cdot 0(9 \cdot 7)^{\star} \\
801 \cdot 2(120 \cdot 9) \\
100 \cdot 4(27 \cdot 2)^{\star \star} \\
27 \cdot 9(8 \cdot 2)^{\star \star} \\
94 \cdot 6(36 \cdot 2)^{\star \star}\end{array}$ \\
\hline
\end{tabular}

${ }^{\star} \mathrm{P}<0.02 v$ patients with hypertension; ${ }^{\star \star} \mathrm{p}<0.001 v$ normal controls.

STRESS THALLIUM SCINTIGRAPHY

Scintigraphy was undertaken with an upright bicycle ergometer and thallium-201 (80 $\mathrm{MBq}$ ) was injected at peak exercise. ECG gated scans were obtained in list mode for the anterior, $45^{\circ}$, and $70^{\circ}$ left anterior oblique views using a mobile gammacamera fitted with a high sensitivity collimator. Reperfusion images were obtained $4 \mathrm{~h}$ later.

CORONARY ARTERIOGRAPHY

Angiography was undertaken using the Judkins technique with five to six views of the left coronary artery and two to three views of the right. Significant coronary artery disease was defined as $>50 \%$ reduction of the internal diameter on visual assessment of any of the three main epicardial coronary vessels.

\section{STATISTICAL ANALYSIS}

Statistical analysis was performed using the Minitab statistical package version $7 \cdot 2 .^{27}$ Results are presented as means (SD). Analysis of variance and non-parametric methods were used and differences were considered significant at $P<0.05$.

\section{Results}

Tables 1 and 2 summarise the clinical characteristics of patients in the present study. The hypertensive and aortic groups were well matched for mean age and ventricular function (fractional shortening) compared with that of the normal controls, but left ventricular mass index was increased $(P<0.001)$. Of the patients with left ventricular hypertrophy, those with aortic valve disease had reduced fractional shortening $(P<0.004)$ and a lower prevalence of significant angiographic coronary artery disease $(13 / 57 v 27 / 47$ patients with hypertension). $\beta$ blocker treatment was continued in 42 patients with hypertension during the study: the use of other antihypertensive medication being similar in this subgroup to that of the remaining 52 patients (calcium antagonists $13 v 26$; angiotensin converting enzyme inhibitors $8 v 13$; diuretics $23 v 31$ ).

Heart rate variability was significantly reduced in patients with left ventricular hypertrophy, whether measured by SDNN, triangular index, or SDANN (all $\mathrm{P}<0.001$ ) (table 1). There was no difference in mean (SD) NN interval between the three groups. There was good agreement between the parameters of heart rate variability used (SDNN $v$ triangular index: $r=0.826$; SDNN $v$ SDANN: $r=0.916$; triangular index $v$ SDANN: $r=0.743$ ) and, therefore, we have shown heart rate variability as triangular index in the figures presented in this paper.

When the normal group and the patients with left ventricular hypertrophy were combined, there was a clear inverse relation between heart rate variability and left ventricular mass index (SDNN: $r=-0.478$, $\mathrm{P}<0.001$; triangular index: $r=-0.437$, $\mathrm{P}<0.001$, fig $1(\mathrm{~A})$; SDANN: $r=-0.438$, $P<0.001)$. This inverse relation between heart rate variability and left ventricular mass index was significant in both the aortic (SDNN: $r=-0.597, \mathrm{P}<0.001$; triangular index: $r=-0.521, \mathrm{P}<0.001$; SDANN: $r=$ $-0.459, P<0.001)$ and the hypertensive groups (SDNN: $r=-0.233, \mathrm{P}<0.05$; triangular index: $r=-0.288, \mathrm{P}<0.01$; SDANN: $r=-0.245, \mathrm{P}<0.05)$.

When patients with aortic valve disease were subdivided according to the predominant valvular pathology (table 2), subjects with aortic regurgitation had greater left ventricular mass index $(P<0.001)$, tended to be older, and to have reduced fractional

Table 2 Clinical characteristics of patients with left ventricular hypertrophy secondary to aortic valvular pathology

\begin{tabular}{|c|c|c|c|}
\hline & Aortic stenosis & Aortic regurgitation & Mixed aortic valve disease \\
\hline $\begin{array}{l}\mathrm{n} \\
\text { Male/Female } \\
\text { Mean (SD) age (years) } \\
\text { Mean (SD) left ventricular mass index }\left(\mathrm{g} / \mathrm{m}^{2}\right) \\
\text { Mean (SD) fractional shortening (\%) } \\
\text { Mean (SD) NN interval (ms) } \\
\text { Mean (SD) SDNN (ms) } \\
\text { Mean (SD) triangular index (ms) } \\
\text { Mean (SD) SDANN (ms) }\end{array}$ & $\begin{array}{l}32 \\
20 / 12 \\
56 \cdot 9(13 \cdot 4) \\
192 \cdot 2(48 \cdot 5) \\
35 \cdot 8(9 \cdot 2) \\
812 \cdot 8(139 \cdot 7) \\
105 \cdot 8(23 \cdot 9) \\
29 \cdot 1(7 \cdot 7) \\
98 \cdot 0(26 \cdot 0)\end{array}$ & $\begin{array}{l}10 \\
6 / 4 \\
62 \cdot 3(7 \cdot 6) \\
285 \cdot 4(92 \cdot 6)^{\star} \\
25 \cdot 8(7 \cdot 7) \\
831 \cdot 8(113 \cdot 0) \\
86 \cdot 6(28 \cdot 7) \\
23 \cdot 0(7 \cdot 4) \\
76 \cdot 1(32 \cdot 1)\end{array}$ & $\begin{array}{l}18 \\
10 / 8 \\
58 \cdot 7(4 \cdot 8) \\
235 \cdot 7(69 \cdot 4) \\
32 \cdot 2(9 \cdot 6) \\
768 \cdot 5(81 \cdot 2) \\
100 \cdot 4(29 \cdot 3) \\
28 \cdot 7(8 \cdot 4) \\
100 \cdot 8(50 \cdot 3)\end{array}$ \\
\hline
\end{tabular}



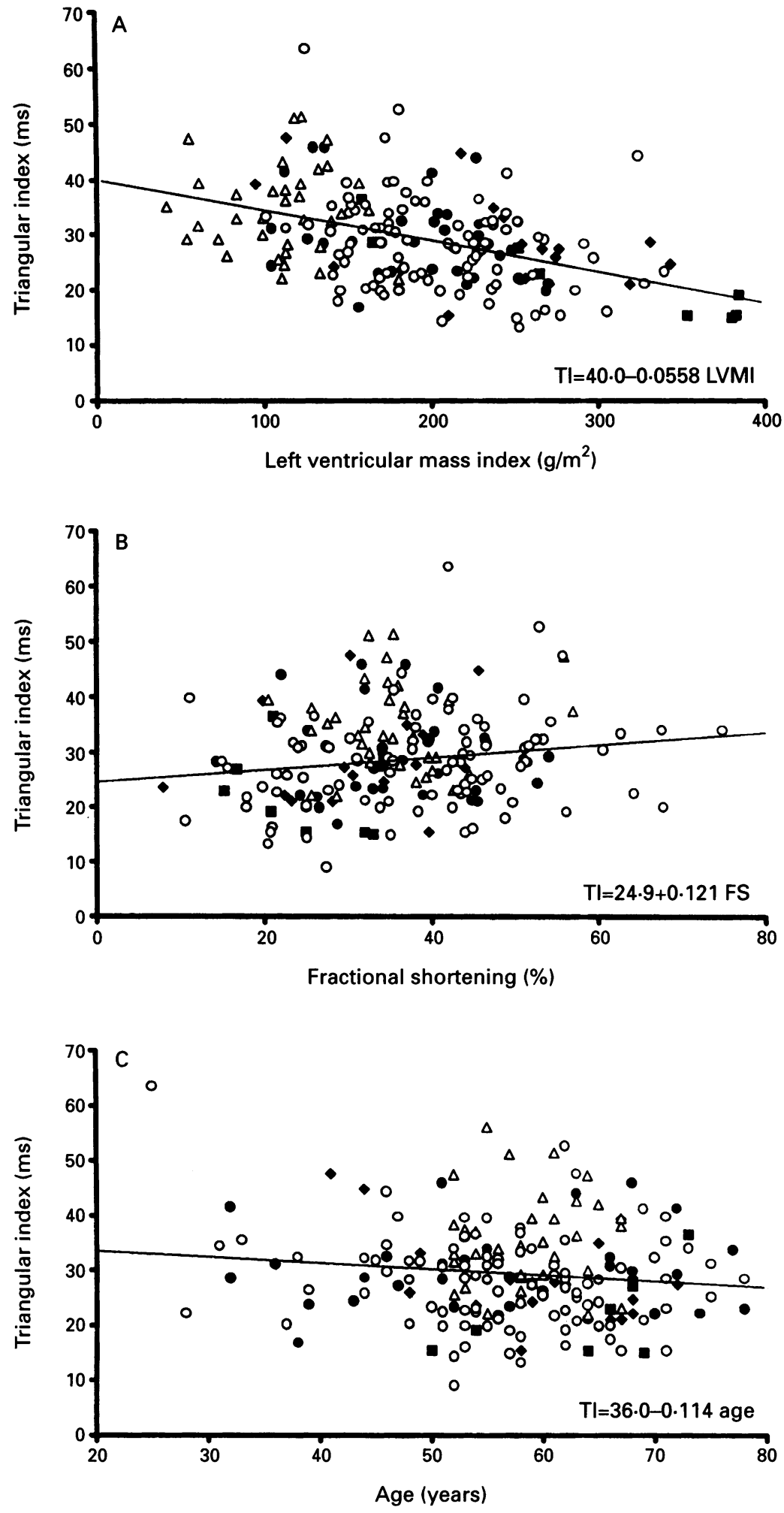

Relation of heart rate variability measured as triangular index and $(A)$ left ventricular mass index (the subgroups are combined to draw the regression line $(r=-0.437$, $P<0.001$ )); (B) fractional shortening (the subgroups are combined to draw the regression line $(r=0.162, P<0.05)$ ); and $(C)$ age (the subgroups are combined to draw the regression line ( $r=-0.127$, not significant)). LVMI, left ventricular mass index; FS, fractional shortening; $\mathbf{Q}$, aortic regurgitation; $\bullet$, aortic stenosis; $\bullet$, mixed aortic valve disease; $\triangle$, normal; $\bigcirc$, hypertension.

shortening and reduced heart rate variability. Aortic regurgitation was associated with a greater end diastolic left ventricular dimension $(66 \mathrm{~mm} v$ aortic stenosis $50 \mathrm{~mm}, \mathrm{P}<$ 0.001 ; $v$ mixed aortic disease $56 \mathrm{~mm}$, not significant). Patients with aortic stenosis appeared to have measured parameters similar to those of patients with hypertension.
Complicated ventricular arrhythmia was documented in $53 \%$ of patients with left ventricular hypertrophy. Patients with and without complex arrhythmia had similar heart rate variability, but there was a small difference in left ventricular mass index $(P<0.02)$ (table 3). Ventricular tachycardia occurred in 12 patients and this group could not be distinguished by measures of heart rate variability (SDNN: $103.7 v 93.9$, not significant; triangular index: $96.6 v 82.4$, not significant; SDANN: $28.0 v 28.2$, not significant) or other parameters.

Significant angiographic coronary artery disease in patients with left ventricular hypertrophy did not affect measures of heart rate variability, and groups were well matched for age, left ventricular mass and function, and mean $\mathrm{NN}$ interval (table 3). Likewise, $\beta$ blocker therapy in patients with hypertension did not affect heart rate variability, but the group receiving therapy had greater fractional shortening and mean $\mathrm{NN}$ interval (table 3 ).

Heart rate variability correlated weakly with fractional shortening (SDNN: $r=0.098$, not significant; triangular index: $r=0.162, \mathrm{P}<$ 0.05 ; SDANN: $r=0.062$, not significant) (fig $1(B))$ and there was no significant correlation with age (SDNN: $r=-0.057$, not significant; triangular index: $r=-0 \cdot 127$, not significant; SDANN: $r=-0.053$, not significant) (fig 1(C)).

Multiple regression techniques were used in an attempt to predict heart rate variability (triangular index) using the variables age, fractional shortening, left ventricular mass index, $\beta$ blocker therapy, and the presence of coronary artery disease (defined as a positive exercise test, reversible thallium defect, or significant angiographic disease). When all groups were combined, the best predictor of triangular index was left ventricular mass index:

Triangular index $=37.76-0.0457 \times$ left ventricular mass index

With the addition of the next best predictor, fractional shortening, there was little improvement in the predictive power of this model. Left ventricular mass index was the most significant predictor in the aortic and hypertensive subgroups, and similar models could be applied.

\section{Discussion}

There is interest in the measurement of heart rate variability as a non-invasive indicator of cardiac autonomic tone. Impaired heart rate variability has been shown to be an important predictor of serious arrhythmic events and of sudden death after myocardial infarction. ${ }^{12} 13$ The current study extends the observations on heart rate variability to a further population at high risk of sudden death: patients with left ventricular hypertrophy secondary to either essential hypertension or aortic valve disease. The finding of significantly lower heart rate variability in patients with left ventricular hypertrophy is in agreement with previous reports in hypertensive left ventricular 
Table 3 Influence of significant ventricular arrhythmia (> 30 ventricular extrasystoles/h, complex ventricular extrasystole, or ventricular tachycardia), angiographic coronary artery disease in patients with left ventricular hypertrophy, and $\beta$-blocker treatment in patients with hypertension on heart rate variability

\begin{tabular}{|c|c|c|c|c|c|c|}
\hline & \multicolumn{2}{|c|}{ Significant ventricular arrhythmia } & \multicolumn{2}{|c|}{ Coronary artery disease } & \multicolumn{2}{|c|}{$\beta$ Blocker therapy } \\
\hline & No & Yes & No & Yes & No & Yes \\
\hline $\begin{array}{l}\text { n } \\
\text { Mean (SD) age (years) } \\
\text { Mean (SD) left ventricular mass index }\left(\mathrm{g} / \mathrm{m}^{2}\right) \\
\text { Mean (SD) fractional shortening (\%) } \\
\text { Mean (SD) NN interval (ms) } \\
\text { Mean (SD) SDNN (ms) } \\
\text { Mean (SD) triangular index (ms) } \\
\text { Mean (SD) SDANN (ms) }\end{array}$ & $\begin{array}{l}73 \\
56 \cdot 0(11 \cdot 1) \\
200 \cdot 4(63 \cdot 9) \\
37 \cdot 2(11 \cdot 5) \\
833 \cdot 3(131 \cdot 9) \\
104 \cdot 1(27 \cdot 1) \\
28 \cdot 9(7 \cdot 9) \\
98 \cdot 7(36 \cdot 1)\end{array}$ & $\begin{array}{l}81 \\
58 \cdot 7(10 \cdot 4) \\
218 \cdot 8(54 \cdot 1)^{\star} \\
35 \cdot 5(13 \cdot 3) \\
817 \cdot 6(154 \cdot 8) \\
101 \cdot 9(35 \cdot 9) \\
27 \cdot 2(9 \cdot 0) \\
92 \cdot 7(37 \cdot 2)\end{array}$ & $\begin{array}{l}64 \\
56 \cdot 2(11 \cdot 0) \\
214 \cdot 1(65 \cdot 6) \\
34 \cdot 6(10 \cdot 1) \\
798 \cdot 2(119 \cdot 5) \\
101 \cdot 1(32 \cdot 0) \\
28 \cdot 2(8 \cdot 9) \\
95 \cdot 7(40 \cdot 5)\end{array}$ & $\begin{array}{l}40 \\
58 \cdot 6(9 \cdot 0) \\
201 \cdot 0(51 \cdot 7) \\
36 \cdot 4(12 \cdot 5) \\
812 \cdot 5(142 \cdot 8) \\
97 \cdot 4(21 \cdot 6) \\
27 \cdot 0(7 \cdot 2) \\
88 \cdot 7(23 \cdot 1)\end{array}$ & $\begin{array}{l}52 \\
58 \cdot 1(8 \cdot 9) \\
208 \cdot 1(53 \cdot 6) \\
35 \cdot 4(14 \cdot 3) \\
772 \cdot 3(123 \cdot 2) \\
101 \cdot 6(36 \cdot 0) \\
27 \cdot 1(7 \cdot 9) \\
95 \cdot 0(40 \cdot 1)\end{array}$ & $\begin{array}{l}42 \\
54 \cdot 6(11 \cdot 5) \\
198 \cdot 5(47 \cdot 4) \\
42 \cdot 1(11 \cdot 9)^{\star \star} \\
923 \cdot 6(152 \cdot 5)^{\star \star \star} \\
108 \cdot 1(33 \cdot 0) \\
29 \cdot 4(9 \cdot 6) \\
97 \cdot 5(33 \cdot 5)\end{array}$ \\
\hline
\end{tabular}

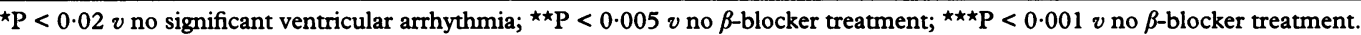

hypertrophy assessed by spectral analysis methods ${ }^{15}$ and in animal studies. ${ }^{28}$ There are no published data on heart rate variability in aortic valve disease, but Airaksinen et $a^{29}$ have reported altered autonomic function in such patients and this is also our experience (AAS Riyami, unpublished data). Heart rate variability was similarly reduced in patients with left ventricular hypertrophy due to pressure overload from either aortic stenosis or hypertension.

We have demonstrated a continuous inverse relation between heart rate variability and left ventricular mass index. This relation is apparent for measurement of heart rate variability by SDNN, triangular index, and SDANN. The correlation was better in patients with aortic valve disease than in those with hypertension, and this may be attributable to a wider range of left ventricular mass index values in the former group because of the inclusion of patients with aortic regurgitation.

Previous studies have demonstrated a reduction in heart rate variability with increasing age, ${ }^{3031}$ in patients with coronary artery disease, ${ }^{25} 32$ and in those with impaired left ventricular function. ${ }^{33}$ In the present study of patients with left ventricular hypertrophy, multivariate analysis demonstrated that left ventricular mass index was the single most important determinant of heart rate variability. Fractional shortening was a much weaker predictor and added little to the power of the multivariate model. Heart rate variability was not affected by angiographic coronary artery disease, patient age, or $\beta$ blocker treatment, although the latter observation is compounded by between group differences in fractional shortening and the mean $\mathrm{NN}$ interval.

The observation of an increased prevalence of ventricular ectopy and ventricular tachycardia in patients with hypertensive left ventricular hypertrophy is consistent with an arrhythmic mechanism as the cause of sudden death. ${ }^{34}$ We were unable to demonstrate any difference in heart rate variability in the left ventricular hypertrophy group between patients with and without complex ventricular arrhythmia. Likewise, no differences in heart rate variability were seen in patients with ventricular tachycardia, although the numbers are small. There is an association between reduced heart rate variability and an increased incidence of ventricular arrhythmia after myocardial infarction, ${ }^{34}$ but the relation in patients with left ventricular hypertrophy is less certain. ${ }^{14}$ The relation of ventricular arrhythmia, left ventricular mass, and heart rate variability requires further exploration.

The study has several potential limitations. It is accepted that SDNN, triangular index, and SDANN, derived directly from heart rate intervals, are broadly based measures of heart rate variability. SDNN, for example, correlates positively with the low frequency component on power spectral analysis $(r=0.85)^{35}$ and conveys important prognostic information. ${ }^{25}$ Analysis of heart rate variability by power spectral methods may provide additional information in patients with left ventricular hypertrophy. Whilst multifactorial analysis suggested that left ventricular mass index was the most important determinant of heart rate variability, inclusion of a larger patient population may have permitted more thorough examination of the possible compounding effects of age, fractional shortening, coronary artery disease, and $\beta$ blocker medication. Information pertaining to ejection fraction is not available for patients in this study.

In conclusion, heart rate variability is reduced significantly in patients with left ventricular hypertrophy secondary to either hypertension or aortic valve disease. There is a continuous inverse relation between heart rate variability and left ventricular mass index. Multivariate analysis demonstrates that left ventricular mass index is the most important determinant of heart rate variability. Disturbances in cardiac autonomic function may contribute to the mechanism of sudden death in patients with left ventricular hypertrophy, and assessment of heart rate variability may prove important in the risk stratification of such patients. Future work should examine the relation between heart rate variability and mortality in patients with left ventricular hypertrophy, and the effect on heart rate variability of changes in left ventricular mass index due to antihypertensive treatment or after aortic valve replacement.

DRW is a British Heart Foundation Friends' Provident Research Fellow. We thank Miss S C McLaughlin for statistical support. 
1 Kannel WB, Gorden T, Offun D. Left ventricular hypertrophy by electrocardiogram: prevalence, incidence and mortality in the Framingham study. Ann Intern Med 1969;71:89-105.

2 Kannel WB, Sorlie P. Left ventricular hypertrophy in hypertension: prognostic and pathogenetic implications (the Framingham study). In: Strauer BE, ed. The heart in hypertension (Boehringer, Mannheim symposium series). Berlin: Springer Verlag, 1981:223-42.

3 Messerli FH, Ventura HO, Elizard DJ, Dunn FG, Frolich ED. Hypertension and sudden death: increased ventricular ectopic activity in left ventricular hypertrophy. $A m \mathcal{F}$ Med 1984;77:18-22.

4 McLenachan JM, Esther M, Morris KI, Dargie HJ. Ventricular arrhythmia in patients with left ventricular hypertrophy. $N$ Engl F Med 1987;317:787-92.

5 Lown B, Verrier R. Neural activity and ventricular fibrillation. $N$ Engl $₹$ Med 1976;294;1165-70.

6 Zipes DP, Levi MN, Cobb LA, Julius S, Peter G, Kaufman PG, et al. Task force 2: sudden cardiac death. Neural and cardiac interactions. Circulation 1987;76 (suppl 1):202-7.

7 Schwartz PJ, Randall WC, Anderson EA, Engle BT, Friedman M, Hartley LH, et al. Task force 4 . Sudden cardiac death. Non pharmacologic interventions. Circulation 1987;76(suppl 1):215-9.

8 Ewing DJ. Heart rate variability: an important new risk factor in patients following myocardial infarction. Clin Cardiol 1991;14:683-5.

9 Martin GJ, Magid NM, Myers G, Barnett PS, Schaad JW, Weiss JS, et al. Heart rate variability and sudden death secondary to coronary artery disease during ambulatory electrocardiographic monitoring. Am $f$ Cardiol 1987;60: 86-9.

10 Ewing DJ, Neilson JM, Shapiro CM, Steward JA, Reid W. Twenty four hour heart rate variability: effect of posture, sleep, and time of day in healthy controls and compariso with bed side tests of autonomic function in diabetic patients. Br Heart $\mathcal{F}$ 1991;65:239-44.

11 Woo MA, William RN, Stevenson G, Mosar DK. Pattern of beat to beat heart rate variability in advanced heart failure. Am Heart $\mathcal{F}$ 1992;123:704-10.

12 Kleiger RE, Miller JP, Bigger JT, Moss AJ and Multicenter Postinfarction Research Group. Decreased heart rate variability and its association with increased mortality after acute myocardial infarction. Am ₹ Cardiol 1987; 59:256-62.

13 Pipilis A, Flather $M$, Ormerod $O$, Sleight $P$. Heart rate variability in acute myocardial infarction and its association with infarct site and clinical course. Am 7 Cardiol 1991;67:1137-9.

14 Cardillo C, Musumevu V. Heart rate variability and ventricular ectopic activity in hypertensive patients. f Hypertens 1989 ; 7 (suppl 6):534-5.

15 Coumel JS, Hermida JS, Wennerblom B, Leenhardts A Maison-Blanche $P$, Cauchemez $B$. Heart rate variability in left ventricular hypertrophy and heart failure, an effects of betablockade. Eur Heart F 1991;12:412-2

16 Pringle SD, Dunn FG, Tweddel AC, Martin W, MacFarlane PW, McKillop, JH, et al. Symptomatic and silent myocardial ischaemia in hypertensive patients with left ventricular hypertrophy. Br Heart ₹ 1992;67:377-82.

17 Riyami AAS. Potential predictors of sudden death in aortic valve disease $[\mathrm{PhD}$ thesis]. Glasgow: University of Glasgow, 1991.
18 Devereux RB, Reicheck N. Echocardiographic determination of left ventricular mass in man: anatomic validation of method. Circulation 1977;55:613-8.

19 Macfarlane PW, Devine B, Latif S, McLaughlin S, Shoat DB, Watts MP. Methodology of ECG interpretation in the Glasgow Program. Methods Inf Med 1990;29:354-61.

20 Devereux RB, Lutas EM, Casale PN. Standardisation of $M$ mode echocardiographic left ventricular anatomic measurements. $\mathcal{F} \mathrm{Am}$ Coll Cardiol 1984;4:1222-30.

21 DuBois D, DuBois EF. A formula to estimate approximate surface area if height and weight be known. Arch Intern Med 1916;17:863-71.

22 McDonald IG, Feigenbaum H, Chang S. Analysis of left ventricular wall motion by reflected ultrasound. Application to assessment of myocardial function. Application to assessment

23 Macfarlane PW, McLung JM, Irving A, Watts MP. Computer assisted analysis of dynamic (24 hours) Computer assisted analysis of dynamic (24 hours) electrocardiology. London: Pitman, 1979:123-6.

24 Lown B, Wolf M. Approaches to sudden death from coronary heart disease. Circulation 1971;41:130-40.

25 Bigger JT, Kleiger RE, Fleiss J, Rolnitzky LM, Steinman RC, Miller JP, and the Multicenter Postinfarction Research Group. Component of heart rate variability measured during the healing of acute myocardial infarction. Am f Cardiol 1988;61:208-15.

26 Cripps TR, Malik M, Farrell TG, Camm AJ. Prognostic value of reduced heart rate variability after myocardial infarction. Clinical evaluation of new analysis method. Br Heart f 1991;65:14-9.

27 Ryan BF, Brian LJ, Thomas AR. Minitab hand book. Boston, MA: PWS Kent Publishing, 1985.

28 Friberg P, Karlsson B, Nordlander M. Sympathetic and parasympathetic influence on blood pressure and heart rate variability in Wistar-Kyoto and spontaneously hypertensive rats. $\mathcal{F}$ Hypertens $1988 ; 6:$ S58-60.

29 Airaksinen KEJ, Ikaheimo NJ, Koistinen MJ, Takkunen $\mathrm{JT}$. Impaired vagal heart rate control in aortic valve stenosis. Eur Heart $\mathcal{F}$ 1988;9:1126-30.

30 Hrushesky WJM, Fader D, Schmitt O, Gilbertson V. The respiratory sinus arrythmia. A measure of cardiac age. Science 1984;224:1001-4.

31 Masaoka S, Lev-Ran A, Hill LR, Gita V, Edward HG. Heart rate variability in diabetes. Relationship to age and duration of disease. Diabetes Care 1985;8:64-8.

32 Hayano J, Sakakibara V, Yamada M, Ohte N, Fujinami T, Yokoyama $\mathrm{K}$, et al. Decreased magnitude of heart rate spectral component in coronary artery disease; its relaspectral component in coronary artery disease; its rela-
tion to angiographic severity. Circulation 1990;81: 1217-24.

33 Nolan J, Flapan AD, Capewell S, MacDonald TM, Neilson JMM, Ewind DJ. Decreased cardiac parasympathetic activity in chronic heart failure and its relation to thetic activity in chronic heart failure and its relation

34 Farrell TG, Bashir Y, Cripps T, Malik M, Poloniecki J, Bennett ED, et al. Risk stratification for arrhythmic events in post infarction patients based on heart rate variability, ambulatory electrocardiographic variables and signal average electrocardiogram. $\mathcal{F}$ Am Coll Cardiol 1991;18:687-97.

35 Kleiger RE, Bigger JT, Bosner MS, Chung MK, Cook JR, Rolnitzky LM, et al. Stability over time of variables measuring heart rate variability in normal subjects. $A m \mathcal{F}$ Cardiol 1991;68:626-30. 